\title{
Group interviews for a cohort hire Lessons learned at the University of Wyoming
}

A fter several years of hiring freezes, the University of Wyoming (UW) Libraries received approval from university administration to recruit three entry-level librarians for our Research and Instruction Services (R\&I) department. Staffing reductions made dedicated librarian support for disciplines unrealistic, so three traditional liaison positions were reframed as learning and engagement, student success, and instructional design librarians to align with the university's emphasis on undergraduate retention. Library administration assembled a committee in January 2018 to conduct a triple search.

Employing a single committee for multiple searches was not a new strategy. The committee chair had worked on two dual searches. Both of those searches had proceeded by interviewing candidates first for one position and then the other. Organizational enthusiasm waned through the process, and new budget cuts halted one of the searches just as the dean prepared to extend an offer. Library leadership wanted to move quickly to fill the R\&I positions. The search committee was charged with facilitating three successful hires before the end of the spring 2018 semester.

The three new job descriptions had some overlap in terms of qualifications and responsibilities, so candidates were encouraged to apply for any or all of the positions. Job announcements were targeted to soon-to-be graduates of library and information science programs.

\section{The group interview}

The search committee met with the university's diversity specialist to ensure a fair screening process. The specialist had recently heard a conference presentation about a recruiting event that brought in a large group of candidates for multiple faculty positions at Michigan State University. Candidates presented on interdisciplinary research in a format similar to TED Talks. The diversity specialist suggested this approach for the libraries' triple search and offered support from her office.

The search chair shared the group interview idea with department heads and administrators, but the reception was mixed. Library faculty searches typically bring two or three candidates to campus for daylong interviews, and librarians attend multiple sessions with candidates. The prospect of sixto-ten days of interviews over several weeks made a condensed approach more appealing, but some librarians expressed concerns about having sufficient opportunity to assess

Cheryl Goldenstein is assistant dean of user services, email: cgold@uwyo.edu, Cassandra Kvenild is assistant dean of education and research services, email: ckvenild@uwyo.edu, Kristina A. Clement is student success librarian, email: kclemen8@uwyo. edu, Samantha Cook is instructional design librarian, scook13@uwyo.edu, and Michelle P. Green is learning and engagement librarian, email: mgreen25@uwyo.edu at the University of Wyoming

(C) 2019 Cheryl Goldenstein, Cassandra Kvenild, Kristina A. Clement, Samantha Cook, and Michelle P. Green 
candidates and about scaring candidates off with a group interview.

We learned that the Health Sciences Library at the University of Colorado Anschutz Medical Campus had recently completed a group interview for a faculty position. The Colorado team had surveyed candidates and library staff about their process and generously shared survey results and their interview schedule. Their experience was positive enough that we decided to move forward. Our search differed in that we would be interviewing for multiple positions.

To address colleagues' concerns about candidate perceptions of a group interview, we polled candidates following the phone interviews. We tried to make clear that their responses would not impact whether they would be selected for an onsite interview. In fact, the search committee had agreed that if any of our finalists were opposed to the idea, we would stick with our traditional interview format. Candidates responded positively, and we began working on a group interview schedule.

\section{Logistics}

Finding dates that worked for multiple candidates to come to campus was our next hurdle because bringing all candidates to campus on the same day was not feasible. We had to keep the interview process the same for all candidates-either all would participate in group interviews or all would come for individual interviews. A few applicants dropped out to accept or continue in other positions. Interview dates fell into place for our remaining candidates. We scheduled four candidates on each of the interview days, though last-minute withdrawals resulted in three each day. We kept the diversity specialist apprised of our activities and invited her to the interviews. Throughout the process, we made every effort on our end not to reveal to candidates who had applied for each of the positions.

Our organization encourages all library employees to participate in faculty interviews.
Everyone has access to application materials for finalists. We invite all to attend candidate presentations and ask questions following the session. All are encouraged to attend catered coffee breaks to welcome candidates. In addition, all librarians attend faculty meetings with candidates. Participants have opportunities to provide feedback about candidates.

The itinerary for the group interview did not vary much from our normal practice, except that we scheduled candidates to meet as a group for some activities. We wanted candidates to learn from each other and start networking early in their careers. We did not want the interview to feel like a competition. Group activities included:

- dinner with the search committee the evening before the interview,

- candidate presentations and the subsequent all-library coffee break,

- optional tours of Laramie and the library, and

- informational meetings about faculty responsibilities and mentoring.

For the presentations, we asked candidates to propose an initiative to support student learning and engagement. The University of Colorado had received some negative feedback for giving candidates the same presentation topic, so we were less prescriptive. We gave some parameters, including tying the initiative to the libraries' strategic plan. We wanted insight into how the candidates would plan and promote a relevant activity, their priorities, and their expectations of the organization.

The presentations were first on the interview itinerary, and candidates drew numbers for presentation order. Candidates had ten minutes to present, followed by five minutes for audience questions, and five minutes transition time. Audience questions were restricted to presentation content. The search chair intervened if questions strayed into candidate qualifications, with hopes the session would feel less like an interview and more like a conference session.

We set up round robin interviews for individual candidates to meet with the li- 
brary faculty, the R\&I department, the R\&I department head, the interim associate dean, and an optional meeting about employee benefits with the business manager. The meetings were shorter than our typical interview schedule, and we built in breaks for candidates and ensured they were escorted between meetings. We wrapped up the schedule with individual candidates going to dinner with a couple of library employees so they could privately ask their final questions about the community and work environment.

\section{Hiring process}

The group interview format allowed library administration to move forward more quickly on the hiring process than would have been the case with individual interviews. One challenge of the group search process stemmed from encouraging candidates to apply for multiple positions. A few candidates were finalists for more than one position. This added a level of difficulty in preparing ranking matrices, particularly with the possibility of a top-ranked candidate either withdrawing from multiple searches at once or rejecting an offer for one or more of the positions.

Continuous communication with university human resources and the employment practices office was invaluable in navigating the complexities of a search with candidates competing for one, two, or even three positions. Campus experts reviewed our matrices and made suggestions for ranking in a way that allowed for flexibility if candidates withdrew.

Offers were extended and accepted as the spring semester wrapped up, and the Libraries' administrative office worked to find start dates to facilitate a cohort model for the new hires.

\section{Staff and candidate perceptions}

Library administration and the search committee thought the group interviews were successful, but we were interested in library staff and candidate perceptions. We developed short, anonymous surveys, borrowing questions from our colleagues at the University of Colorado.

We wanted to know whether library staff felt they were able to make informed hiring recommendations after the abbreviated interview process. Fifteen employees completed our survey. All but one said they had enough or more than enough time to assess each candidate. Comments about the group presentation were positive. Some respondents said they missed questions and responses they would normally hear in multiple meetings with candidates, but the reduced time spent in interviews was worth the trade-off.

Our efforts to avoid telling candidates who had applied for which positions caused some confusion for staff. Email announcements indicated the finalists for each position, but one staff respondent lamented not knowing this information for the presentations. Another noted that reading application materials in advance was particularly helpful in getting to know the candidates before the condensed format interviews. We will encourage staff to prepare ahead of time for future interviews.

We emailed a survey to the finalists shortly after the campus visit and before offers were extended, and almost all responded. We asked about their initial reaction to the idea and what they did and didn't like about the process after going through it. Our three new librarians revisited the survey questions after they had been on the job for a few months.

We were a bit surprised that several candidates admitted initial trepidation about a group interview, since all had responded positively when we emailed them with the idea. One of our new librarians shared, "After giving it some thought, I decided that it might actually be advantageous to participate in a group interview because it had the potential to speed up the interview and hiring process ... the waiting game to hear back from search committees was agonizing, and anything I or someone else could do to speed the process along would have been appreciated."

Candidate perceptions about the interview itself were positive. Candidates said they en-

(continues on page 164) 


\section{Notes}

1. Jean Kirnan, Steven Siminerio, and Zachary Wong, "The Impact of a Therapy Dog Program on Children's Reading Skills and Attitudes toward Reading," Early Childbood Education Journal 44, no. 6 (2016): 637-651; Judy A. Rollins, "Brilliant, Absolutely Brilliant: Reading to Dogs," Pediatric Nursing 42, no. 2 (2016): 58.

2. Laura Bassette and Teresa TaberDoughty, "The Effects of a Dog Reading Visitation Program on Academic Engagement Behavior in Three Elementary Students with Emotional and Behavioral Disabilities: A Single Case Design," Child \& Youth Care Forum 42, no. 3 (2013): 239-56; Donna Lamkin, "Fostering Literacy Learning with Three Middle School Special-Education Students Using Therapy Dogs as Reading Partners" (dissertation, State University of New York, 2017).
3. Stephen Messenger, "Something Really Amazing is Happening at This Animal Shelter," last modified March 9, 2016, https:// www.thedodo.com/kids-read-to-shelter -dogs-1620612867.html.

4. Juliana. M. Hypes, "The Effects of the Human Voice on the Behavioral Indicators of Stress in Dogs Housed in an Animal Shelter" (thesis, West Virginia University, 2015).

5. Stephen Messenger, "Something Really Amazing is Happening at This Animal Shelter," last modified March 9, 2016, https:// www.thedodo.com/kids-read-to-shelter -dogs-1620612867.html.

6. Humane Society of Missouri, "Shelter Buddies Reading Program Guide," accessed October 15, 2017, http://hsmo.org /shelterbuddies/.

7. Ibid., Humane Society of Missouri, http://hsmo.org/shelterbuddies/.z

("Group interviews. . ., " continues from page 152)

joyed meeting each other and felt a sense of camaraderie, though comparing themselves to the competition was unavoidable. One of our new librarians shared a unique take on the situation: "I liked having less pressure, in a sense. With the attention of interviewers being divided instead of solely focused on me, I felt reduced stress."

Candidates said they felt they were able to make a case for themselves during the campus visit. None of them made changes to their presentations or interview strategies based on observing their competitors. According to one of the new hires, "I liked that we got to listen to each other's presentations because I learned a lot from them. But we met with the faculty, the department, and department head alone, which gave us time to express ourselves without the other candidates being there. It was a good mix of group and individual time."

When asked about disadvantages of the group interview or what they would do to change it, respondents expressed satisfaction with their experience. A couple mentioned potential pitfalls of group dynamics and less time to make an impression, though one added that UW Libraries made them feel "genuinely welcomed and seen as an individual." Other suggestions related to reducing the sense of competition through scheduling or discouraging candidates from sharing information about positions. One recommended that group interviews should be used only if multiple positions are available.

Responses were mixed regarding our strategy to avoid sharing information about the other candidates. One preferred meeting all the candidates and knowing from the beginning who applied for what. Others said they liked not knowing, including one of our new hires: "One candidate and I asked each other . . . even right after I told this person, I wish I had declined to answer! I felt something shift between us but sensed no animosity. In spite

(continues on page 168) 